\title{
Propuesta de clasificación tipológica de obras arquitectónicas del caribe costarricense en la ciudad de Limón, construidas a principios del siglo $\mathrm{XX}$
}

Proposal for typological classification of architectural buildings of the Costa Rican Caribbean in the city of Limón, built in the early 20th century

Ariel Valerín-Víquez¹, Dominique Chang-Albizurez ${ }^{2}$

Valerín-Víquez, A; Chang-Albizurez, D. Propuesta de clasificación tipológica de obras arquitectónicas del caribe costarricense en la ciudad de Limón, construidas a principios del siglo XX. Tecnología en Marcha. Edición especial. Escuela de Arquitectura y Urbanismo, Diciembre 2020. Pág 26-36.

doi) https://doi.org/10.18845/tm.v33i8.5506

1 Instituto Tecnológico de Costa Rica, Costa Rica. Correo electrónico: ariel_valerin@hotmail.com. 


\title{
Palabras clave
}

Valor patrimonial; Expresión formal; Arquitectura caribeña costarricense; Tipología arquitectónica; Identidad caribeña.

\section{Resumen}

Esta publicación expone los resultados de la práctica de vinculación profesional, relacionada con el proyecto "Conservación de la arquitectura caribeña costarricense a partir de la aplicación de técnicas de avanzada para el estudio de los agentes causantes de lesiones en las edificaciones". El trabajo pretendió analizar las expresiones formales de los elementos arquitectónicos y de las adaptaciones climáticas presentes en la arquitectura de estilo caribeña costarricense, particularmente en las elevaciones principales de dichos inmuebles; para el establecimiento de una clasificación tipológica más específica, según el proyecto al que está vinculado, de las edificaciones construidas a principios del siglo XX en el Centro Histórico de la ciudad de Limón y su primer ensanche.

Se clasificaron veintiocho inmuebles en seis tipologías diferentes; mediante una matriz multicriterio que relacionó las expresiones formales encontradas con dos aspectos de la composición arquitectónica: la función utilitaria y la vinculación de las edificaciones con el contexto. Donde el primer elemento de relación hace referencia a si el inmueble es institucional o residencial y de qué tipo; y el segundo aspecto, entendido como la adaptación del edificio, en función del modo de vida de los usuarios, al lugar de emplazamiento. Por último, el trabajo consideró aquellas expresiones formales que permiten diferenciar dos objetos arquitectónicos que se encuentran en una misma tipología.

\section{Keywords}

Patrimonial value; Formal expression; Costa Rican Caribbean architecture; Architectural typology; Caribbean identity.

\begin{abstract}
This publication presents the results of the practice of professional engagement, related to the project "Conservation of the Costa Rican Caribbean architecture from the application of advanced techniques for the study of agents causing injury in buildings". The work intended to analyze the formal expressions of the architectural elements and of the climatic adaptations present in the Costa Rican Caribbean-style architecture, particularly in the main elevations of said buildings; for the establishment of a more specific typological classification, according to the project to which it is linked, of the buildings built at the beginning of the 20th century in the Historic Center of the city of Limón and its first expansion.

Twenty-eight properties were classified into six different typologies; through a multi-criteria matrix that related the formal expressions found with two aspects of the architectural composition: the utilitarian function and the link of the buildings with the context. Where the first relationship element refers to whether the property is institutional or residential and of what type; and the second aspect, understood as the adaptation of the building, depending on the way of life of the users, to the location. Finally, the work considered those formal expressions that allow differentiating two architectural objects that are in the same typology.
\end{abstract}




\section{Introducción}

En los últimos años el Tecnológico de Costa Rica (TEC) ha buscado poner en valor, mediante diferentes proyectos de investigación y extensión, el patrimonio tangible e intangible del caribe costarricense; en este contexto la Escuela de Arquitectura y Urbanismo ha puesto especial atención en los objetos arquitectónicos de la ciudad de Limón ${ }^{3}$ y su primer ensanche. El presente artículo desarrolla los resultados de la Práctica de Vinculación Profesional (PVP) del autor principal de este, el cual es parte del proyecto aprobado por la Vicerrectoría de Investigación y Extensión del TEC "Conservación de la arquitectura caribeña costarricense a partir de la aplicación de técnicas de avanzada para el estudio de los agentes causantes de lesiones en las edificaciones" coordinado por la Dra. Arq. Kenia García Baltodano.

Por lo tanto, el desarrollo de la PVP se basó en la delimitación geográfica y temporal del proyecto anteriormente mencionado, específicamente [1] definen como ámbito de estudio físico el Centro Histórico $(\mathrm{CH})$ y el primer ensanche de la ciudad de Limón. En este sentido se entiende por $\mathrm{CH}$ de Limón la delimitación propuesta por [2], en la cual se incluye la trama urbana conformada en 1929, delimitada por la Avenida 7 al norte, la calle 7 al oeste y el mar Caribe al sur y al este. Por otro lado, el proyecto considera como "primer ensanche" el desarrollo urbano al norte de la estación del ferrocarril conocido como Jamaica Town y la Zona Americana, lugar donde actualmente se ubica el Hospital Tony Facio Castro. Temporalmente [1] consideraron dentro del proyecto de investigación las obras construidas entre 1871 y 1940.

Según [3] el sector anteriormente descrito posee gran riqueza en recursos patrimoniales, entre los que destaca el patrimonio histórico arquitectónico. En este sentido [4] indican que, la arquitectura caribeña costarricense "constituye una de las tipologías más características e identitarias de la ciudad de Limón, basada en el uso de la madera y la adaptación arquitectónica a las condiciones ambientales de la zona". Además, [4] aseguran que Limón es particularmente un espacio multicultural y pluriétnico, debido a los procesos de migración de fuerza laboral a la zona a principios del siglo XX, como resultado del modelo económico y comercial de la época, que involucró el asentamiento de la United Fruit Company (UFCO) producto del enclave bananero.

Según [4] esta vinculación de la UFCO propició la introducción de diferentes estilos arquitectónicos a Costa Rica; como el neoclásico, el victoriano caribeño o el ecléctico, pues esta compañía importaba edificaciones por catálogo que adaptaban a las condiciones contextuales de Limón. En otras palabras, el mestizaje genético y cultural entre poblaciones autóctonas, criollas, europeas y africanas se manifestó en diferentes ámbitos, entre estos, la arquitectura caribeña en donde se amalgamó una variedad de soluciones e identidades integradas de modelos importados con técnicas, sistemas constructivos y adaptaciones locales a nivel climático y sociocultural.

Como ejemplo de estas adaptaciones, está el caso particular de los corredores y galerías, estos espacios bordean, ya sea, todo el perímetro de la obra o sólo un tramo y que tienen como fin proteger al inmueble de las condicionantes climáticas propias del Caribe: "elemento predominante, con sutiles variaciones en todo el Caribe, como respuesta climática para refrescar los interiores, alejar el sol de las paredes y protegerse de los torrenciales aguaceros tropicales" [5]. Sin embargo, [5] rescata la función social por la cual surgieron este tipo de espacios, en donde, se vinculaba la dinámica del hogar con la que se desarrollaba en la sociedad, generando estos espacios público-privados para el esparcimiento de sus habitantes. 
Si bien la arquitectura caribeña se manifiesta de manera similar en toda la región, [4] aseguran que una notable diferencia en Costa Rica es la presencia de una ornamentación menos recargada si se compara con la del resto del caribe. Así mismo, estos investigadores indican que los elementos arquitectónicos característicos de esta arquitectura son "los corredores y las galerías, los detalles decorativos de influencia victoriana (barandas, celosías, ménsulas, cresterías y dobles aleros) y los techos con pendientes pronunciadas" [4].

En síntesis, la arquitectura caribeña costarricense se asocia a espacios construidos con influencia de estilos anglo-caribeños; pero menos ostentosos que sus similares en la región; perceptiblemente amplios, luminosos, ligeros y abiertos a toda la dinámica presente a su alrededor y que solventa en gran medida los requerimientos ya impuestos por su contexto, ya sea este natural, construido o social.

El trabajo de la PVP consistió en analizar las expresiones formales de los elementos arquitectónicos y de las adaptaciones climáticas de los objetos construidos de estilo caribeño costarricense, presentes en las elevaciones principales de dichos inmuebles; con el objetivo de establecer una clasificación tipológica más específica, según la obra a la que esté vinculada. Las tipologías que se describen en el presente documento permiten un acercamiento conceptual y técnico para la planificación de proyectos de intervención que permitan la conservación de los inmuebles con estas características; lo cual es importante ya que, como lo recomienda [6], para este tipo de proyectos se considera como buena práctica el investigar, esto involucra tener identificadas y delimitadas las características del tipo de inmueble que se pretende intervenir, elementos que se ofrecen como resultado de la investigación para la arquitectura caribeña costarricense. Además, estas tipologías podrían ser una base para reinterpretar los valores arquitectónicos analizados y proponer una obra contemporánea adaptada al entorno particular del caribe costarricense.

\section{Materiales y métodos}

La metodología de trabajo de la PVP se basó en una investigación cualitativa. Asentada, principalmente, en el desarrollo de un proceso particular de análisis de todos los inmuebles que se seleccionaron dentro de la muestra establecida. Autores como [7], apoyan esta singularidad de este tipo de investigación al mencionar que:

"Desde un nivel técnico, preocupado por las técnicas, instrumentos y estrategias de recogida de información, la investigación cualitativa se caracteriza por la utilización de técnicas que permitan recabar datos que informen de la particularidad de las situaciones, permitiendo una descripción exhaustiva y densa de la realidad concreta objeto de investigación".

Por lo que, se volvió esencial, el nivel de acercamiento que se le dio a cada inmueble en particular, para así poder entender y describir el fenómeno en estudio; el cual, se relacionaba a cómo se habían presentado las características peculiares de la arquitectura caribeña de principios del siglo XX, en el territorio costarricense, propiamente en el Centro Histórico de Limón y su primer ensanche. Lo que implicó que esta investigación se realizara por medio del enfoque hermenéutico, el cual, como lo menciona [8]: "El pensamiento hermenéutico interpreta, se mueve en significados no en datos, está abierto en forma permanente frente al cerrado positivo. Se interesa por la necesidad de comprender el significado de los fenómenos y no solamente explicarlos en términos de casualidad". De ahí la importancia de no, solamente, mencionar las expresiones formales encontradas en dichos inmuebles; sino también entender por qué se llevaron a cabo. 
El principal instrumento del cual se hizo uso fue el análisis de contenido. Según [9], este concepto hace referencia a ser:

"... una técnica de interpretación de textos, ya sean escritos, grabados, pintados, filmados..., u otra forma diferente donde puedan existir toda clase de registros de datos, trascripción de entrevistas, discursos, protocolos de observación, documentos, videos... el denominador común de todos estos materiales es su capacidad para albergar un contenido que leído e interpretado adecuadamente nos abre las puertas a los conocimientos de diversos aspectos y fenómenos de la vida social".

El instrumento descrito anteriormente, permitió analizar la documentación gráfica con la que contaba el proyecto de investigación al que se vinculó la PVP. De este modo, se dio un primer acercamiento y análisis de las características o expresiones formales, propias de este tipo de obras arquitectónicas, en los inmuebles que abarca este proyecto de investigación.

Dicha documentación, hace referencia específicamente a las fichas técnicas de los inmuebles seleccionados y a un glosario de los términos propios de la arquitectura caribeña costarricense. Los cuales son dos de los instrumentos elaborados y aplicados por el proyecto de investigación con el que se relaciona este trabajo; para este fin se desarrolló la siguiente metodología:

En primer lugar, se realizó una selección de inmuebles que cumplieran las condiciones requeridas por la investigación, los cuales fueron evaluados según el periodo y su materialidad.

Posteriormente, se realiza un análisis de la autenticidad de la obra y de los elementos que la componen, para una mayor exactitud de los resultados.

Como tercer paso, se evaluaron dichos elementos según la relevancia y continuidad en la que se presentan, a nivel de fachada, en los inmuebles analizados.

Seguidamente, se da una agrupación de estas características en tres grandes bloques para la organización de la información.

Por último, se subdividen los bloques en aspectos más puntuales, con el fin de no perder ningún rasgo característico de esta arquitectura.

El establecimiento de estas características permitió la definición de las propuestas tipológicas; las cuales, eran el objetivo principal de este trabajo. Se tomó como referencia las palabras de [10], al definir una tipología arquitectónica o tipo de arquitectura como: "un reconocimiento de unos rasgos comunes que permiten la identificación de las obras arquitectónicas que comparten la misma estructura formal".

Dicha estructura formal, parte desde cómo se concibió la obra edilicia, hasta su realización o construcción. De ahí que, dentro de las expresiones formales tomadas en cuenta, resaltaron aquellas formas de concebir y analizar el contexto inmediato, en donde se emplazaba la edificación y las condiciones que este presentaba.

En la figura 1, se muestran aquellas expresiones formales tomadas en cuenta, donde algunas van dirigidas a responder a uno de los condicionantes más fuertes en el trópico caribeño, las precipitaciones. Por lo que se inicia con aquellas soluciones arquitectónicas que respondieran a esta necesidad, tales como: las cubiertas, en donde se toma en cuenta la pendiente y las variantes que puedan presentar; tales como: el uso de buhardilla ${ }^{4}$ o de monitor. Por otra parte, se muestra el uso de antealeros, ya sea presentes en la totalidad del inmueble o sólo en un tramo.

4 Concepto ajustado en el proyecto de investigación, durante la realización de la PVP, ya que "Buhardilla" por definición, es un espacio habitable; y en Limón, este tipo de espacios no se presentaron. Por lo cual, se implementó el término de "Ventila", ya que hace referencia a un espacio destinado única y exclusivamente a mejorar la ventilación del espacio interno del inmueble. Por lo cual, en la figura 1 aún se maneja como Buhardilla, pero en la figura 3 ya aparece el término de Ventila. 
También, se incorporaron aquellos espacios intermedios y permeables entre la zona pública y privada de cada inmueble, como lo son los corredores y galerías; los cuales, llegan a jugar un papel determinante en dos aspectos: el primero, a nivel climático, permite la regulación de la temperatura del espacio interno al no exponer directamente las caras externas de los distintos aposentos de la obra construida a la radiación solar; y en segundo lugar, juega un papel determinante en la dinámica social, al ser un lugar donde se fusionan e interactúan las dinámicas propias de la edificación (privadas) con su contexto inmediato (públicas).

De la misma manera, se contempló la forma en cómo estas obras edilicias fueron concebidas para responder a la condición topográfica que presenta la zona del Caribe, por lo que se toma en cuenta la elevación de las edificaciones, ya sea por medio de pilotes o de zócalo. Así como la disposición espacial de dichas obras, si son de un nivel o de dos niveles, ya que eso incide en el modo de vida de las personas y cómo se relacionaban con su contexto inmediato.

Finalmente, se tomó en cuenta la composición general de la fachada, en términos de simetría, ya que dependiendo de la distribución de las otras expresiones formales y de la función utilitaria que presenta la edificación, esta variaba.

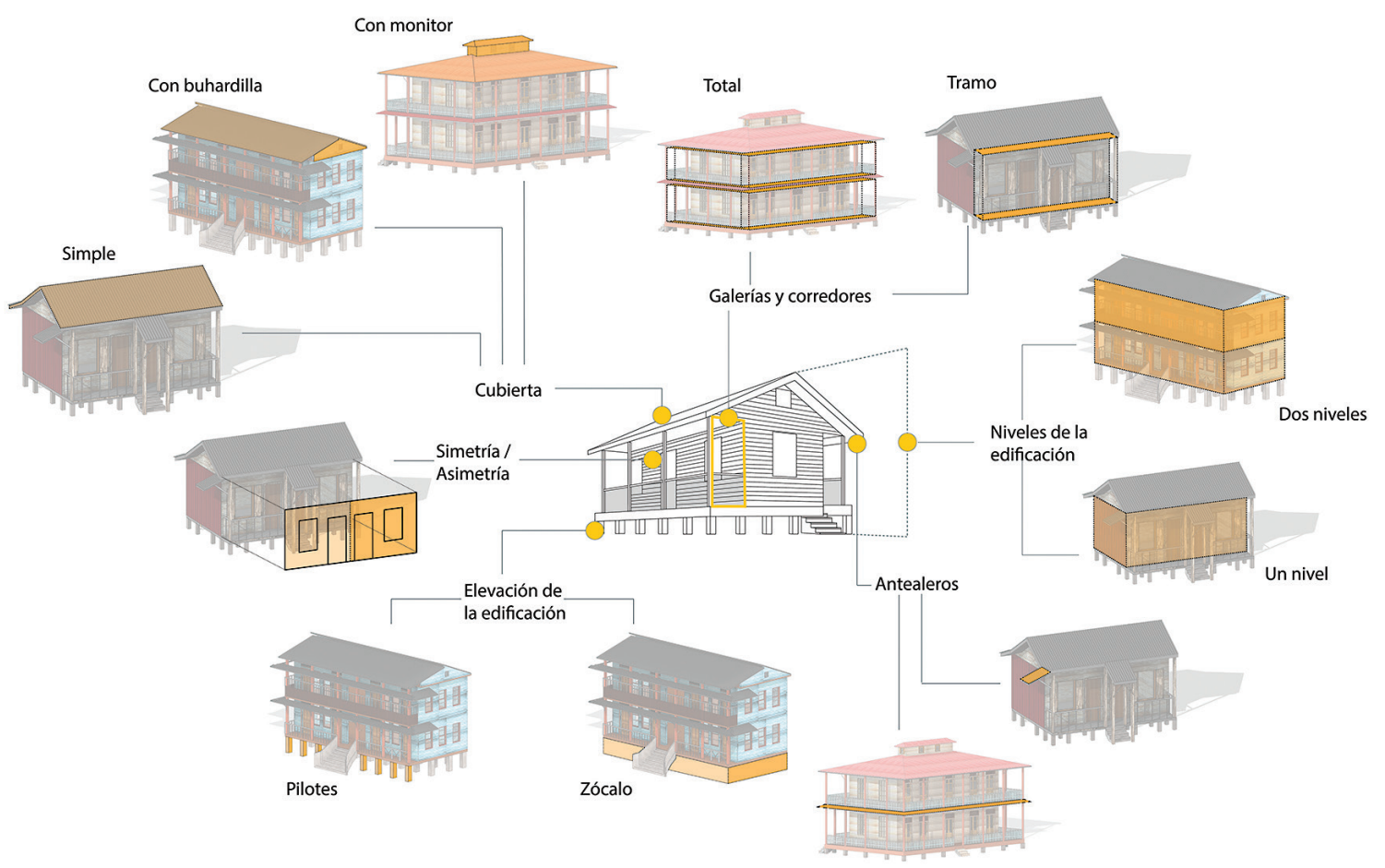

Figura 1. Esquema de las expresiones formales orientadas al emplazamiento, en temas topográficos y climáticos; así como de la relación de la obra con su contexto, producto de la PVP.

Por otro lado, como se muestra en la figura 2, se tomaron en cuenta aquellas características propias de la arquitectura de estilo caribeña y que van dirigidas a solventar una necesidad de confort o simplemente, de imagen. Tales como: implementación de detalles constructivos simples como los barrotes, en "equis" o en paralelo; las cuales son aplicadas en estructuras terciarias como las barandas, principalmente. Así como detalles más complejos, como el calado y molduras, presentes en diversos niveles estructurales, desde columnas, hasta barandas y sobrepuertas; dichas técnicas jugaron un papel estético dentro de la imagen de la edificación. 
Además, se presentan aquellos detalles constructivos orientados al confort climático dentro de la edificación, tales como el uso de petatillos, celosías y rejillas.

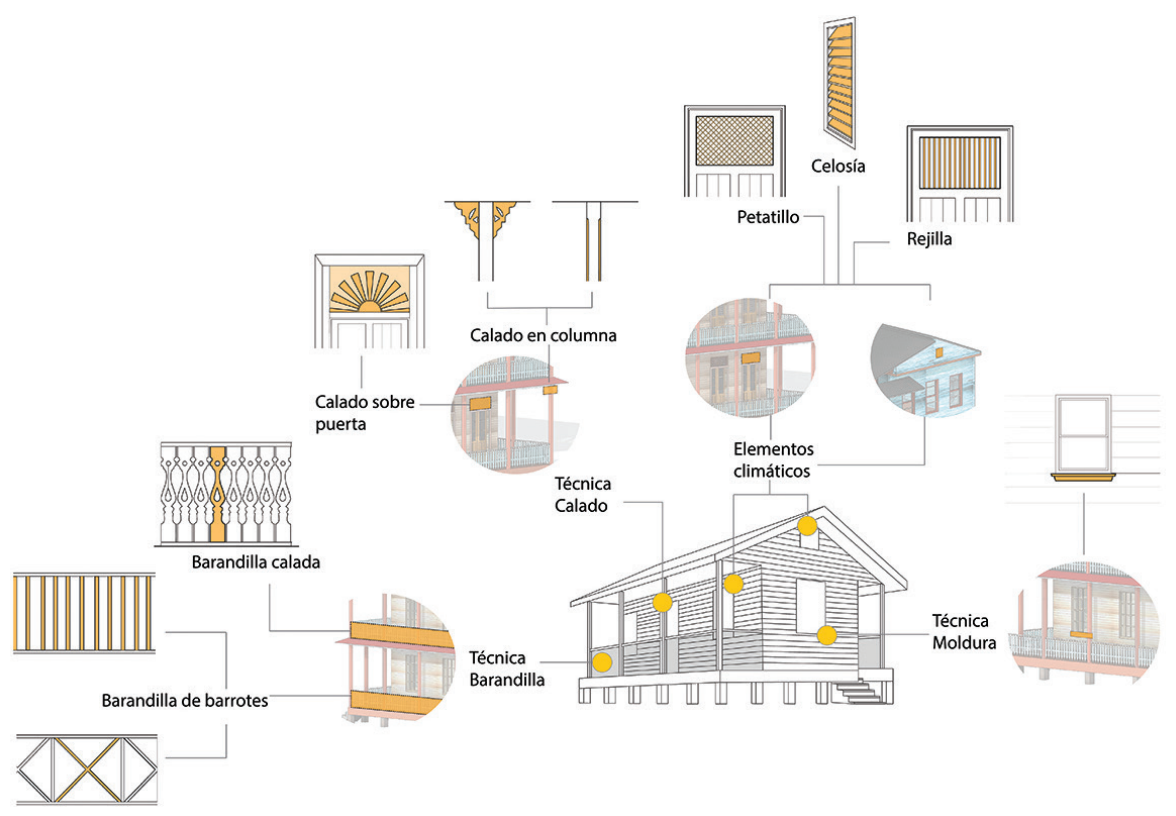

Figura 2. Esquema de las expresiones formales orientadas al uso de detalles constructivos que potencien la imagen de la edificación o el confort climático del espacio interno, producto de la PVP.

Dichas expresiones, a su vez, recalcan el concepto que trabajan [11] sobre tipología arquitectónica, cuando mencionan que los aspectos característicos que se tomen en cuenta no sólo fueran vistos desde el punto de vista constructivo, sino entendiéndolos con respecto al impacto que estas expresiones tuvieron en el día a día de sus pobladores:

"En este sentido la tipología arquitectónica se fundamenta en las características recurrentes de las construcciones, considerándolas como manifestación de los modos de vida y relación del hombre con su medio; es decir, analiza las soluciones arquitectónicas singulares, pero tratando de estructurar sus vínculos con el contexto general en que se ubican. Trata de identificar las relaciones organizativas que presentan los espacios edificados mediante la búsqueda de los nexos existentes entre los diversos casos, fragmentándose el campo de estudio para su posterior recomposición dentro de una organización generalizadora".

Todo este análisis se aplicó en veintiocho inmuebles, de los cuales, algunos no continuaron en pie durante el transcurso de la investigación, pero se contó con la información suficiente para ser tomados en consideración dentro de este análisis y su posterior clasificación.

La población meta, a la que pretende contribuir los resultados de la investigación, es a profesionales y estudiantes en arquitectura e ingeniería con interés en la investigación entorno al patrimonio construido en el caribe costarricense, específicamente en la CH de Limón y su primer ensanche. 


\section{Resultados}

El trabajo llevado a cabo para la generación de una propuesta de clasificación tipológica de obras arquitectónicas del caribe costarricense en el $\mathrm{CH}$ y primer ensanche de la ciudad de Limón, que fueron edificadas a principios del siglo XX, obtuvo como principales resultados:

- Generación de una matriz multicriterio, donde se evalúa la aplicación de cada expresión formal relevante dentro de la arquitectura de estilo caribeña, en los inmuebles seleccionados.

- Visualización de cómo se distribuyen los inmuebles según cada expresión identificada, ya sea en elementos arquitectónicos como de adaptaciones climáticas, presentes en las elevaciones principales de las edificaciones analizadas.

- Propuesta de clasificación tipológica de la arquitectura de estilo caribeño costarricense, construidas a principios del siglo XX en el Centro Histórico de Limón y su primer ensanche.

Con respecto a la matriz multicriterio, esta fue relevante para generar un análisis independiente de cada inmueble, lo que propició disponer del material necesario para generar la propuesta sobre las tipologías arquitectónicas de aquellas obras de estilo caribeño costarricense. Además, permitió generar un informe gráfico por cada inmueble, en donde se encuentran mayores especificaciones formales de la obra construida y así, diferenciarlas entre sí, aunque estas pertenezcan a una misma tipología.

Específicamente, para la generación de la propuesta tipológica, se tomaron en cuenta aspectos como: la función utilitaria de los inmuebles, la cual viene dada de la concepción o finalidad de este; de las cuales, destacan aquellas obras dirigidas a solventar la necesidad habitacional de sus pobladores, siendo estas un total de veintiséis inmuebles. Los cuales se dividen en seis residencias unifamiliares, once residencias multifamiliares tipo dúplex y, por último, nueve residencias multifamiliares. Adicionalmente, las dos obras edilicias restantes, pertenecen a inmuebles de índole no residencial. Cabe destacar que de esta distribución se derivaron los dos grandes bloques propuestos para las clasificaciones tipologías de las obras arquitectónicas de estilo caribeño costarricense.

Por otra parte, y según [11], las expresiones formales que se tomaron en cuenta, debido a que reflejan el modo de vida de las personas que habitaron estos espacios, fueron dos. En primer lugar, la permeabilización, entendida como la implementación de corredores o galerías en las edificaciones; la cual, se distribuye de la siguiente manera: dos inmuebles que no presentan esta característica, dos edificaciones que presentan una permeabilidad total por medio de galerías y, por último, veinticuatro obras presentan una permeabilidad parcial o en tramo, por medio de corredores.

La segunda expresión formal fueron los niveles que presenten dichas obras en el Caribe costarricense, de las cuales veintiún edificaciones son de un solo nivel y las siete restantes, presentan dos niveles de altura. Se puede apreciar la prevalencia que tuvieron las construcciones de un único nivel y que fueron permeables a la dinámica urbana por medio de corredores, en la mayoría de las obras construidas en madera en el $\mathrm{CH}$ de Limón y su primer ensanche, a principios del siglo XX.

Una vez, llevada a cabo la correspondencia entre forma y función de estos inmuebles, y las variaciones que presentaron, se obtuvo un total de seis tipologías de dichas obras arquitectónicas, las cuales se mencionan a continuación: 
Tipología no residencial

- Inmueble no residencial de dos niveles, permeable a su contexto por corredor.

- Inmueble no residencial de dos niveles, permeable a su contexto por galería.

Tipología residencial

- Inmueble residencial multifamiliar tipo dúplex, de un nivel, permeable a su contexto por corredor.

- Inmueble residencial unifamiliar, de un nivel, permeable a su contexto por corredor.

- Inmueble residencial multifamiliar, de un nivel, permeable a su contexto por corredor.

- Inmueble residencial multifamiliar, de dos niveles, permeable a su contexto por galería.

Como se mencionó anteriormente, dichas tipologías llegaron a ser complementadas con otras características propias de la arquitectura caribeña y que permitieron profundizar en las expresiones formales e individuales de cada inmueble analizado y así, brindar la posibilidad que distinguir las edificaciones entre sí, aunque pertenezcan a una misma tipología. Tales características fueron: el uso de antealeros como extensión de la cubierta, la disposición y configuración de la cubierta, la simetría de la edificación reflejada en fachada, la elevación de la obra con respecto al suelo y la formalización de algunos detalles aplicados a elementos específicos, que potencien el confort del espacio o la imagen de la inmueble; como el calado (intención estética) o el uso de petatillo (intención de confort bioclimático), entre otras.

El resultado de este análisis particular, fue una ficha gráfica de cada inmueble, elaborada específicamente para la PVP. Cada una de estas fichas, se identifican en su extremo superior izquierdo con la forma de codificación propuesta por [1], quienes definen dos tipos de categorías para estos inmuebles, las cuales son: Tipo 1, que hace referencia a aquellas edificaciones que no han sido nada o poco transformadas, por lo que dichas obras cumplen en su mayoría con las características de la arquitectura caribeña costarricense; y el Tipo 2, que son aquellas obras edilicias que han sufrido algunas transformaciones, por lo que cumple parcialmente con las características de la arquitectura caribeña costarricense. A continuación, se muestran, como referencia, unas de estas fichas.

En la figura 3, se muestra un inmueble que pertenece a la categoría Tipo 1, en la parte principal de la ficha se encuentra la fotografía del edificio; de la cual, se extraen los diagramas de aquellas expresiones formales más relevantes que dicha obra posee y estos son descritos en la columna que se encuentra en el costado izquierdo de la ficha. Dentro de las características propias de la arquitectura caribeña costarricense que posee, son: un corredor continuo en su fachada principal, una cubierta con alto porcentaje de pendiente para la rápida evacuación del agua pluvial y posee una ventila para aumentar el confort del espacio interno; presenta el uso de detalles como el calado, como parte de la concepción e intención estética de la obra; así como el uso de celosías como estrategia climática y por último, de manera general, presenta una fachada simétrica.

Por otra parte, la figura 4 muestra un inmueble de categoría Tipo 2, el cual presenta una cubierta simple de dos aguas y con pendiente pronunciada, rejillas como respuesta ante las circunstancias climáticas, un corredor que se encuentra segmentado por la división de residencias, presenta aleros como extensión de la cubierta para manejar más eficazmente la precipitación de la zona; y su fachada es simétrica y simple, ya que se limita al uso de barrotes.

Como se puede observar, ambas edificaciones tienen diferencias formales en las características que se analizaron; sin embargo, ambas pertenecen a una misma tipología arquitectónica, la cual sería: Inmueble residencial multifamiliar tipo dúplex, de un nivel, permeable a su contexto 
por corredor. Lo anterior es importante, pues de esta manera, no se excluyen aquellas características formales que, por su intencionalidad, no llegan a impactar en gran medida dentro de una dinámica social de esta localidad, pero llegan a ser reflejo de cómo una cultura, o en este caso cómo todas las culturas que influyeron, entendieron el lugar donde se emplazarían y de esta forma, lograrse adaptar a su contexto.

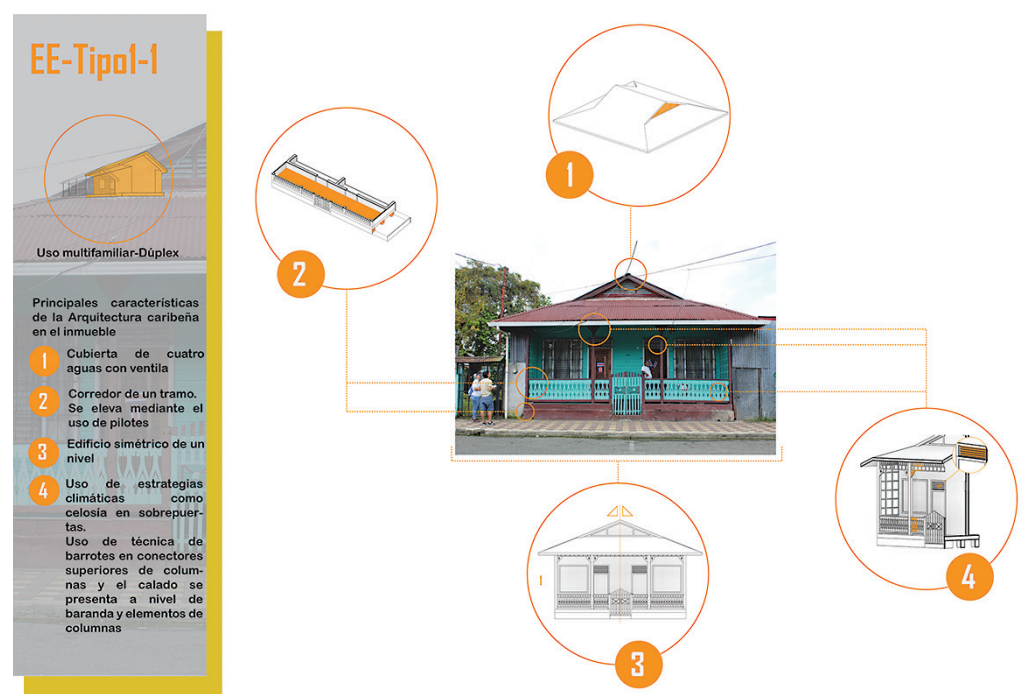

Figura 3. Ficha gráfica sobre las características caribeñas particulares, presentes en una vivienda en el Centro Histórico de Limón, producto de la PVP.
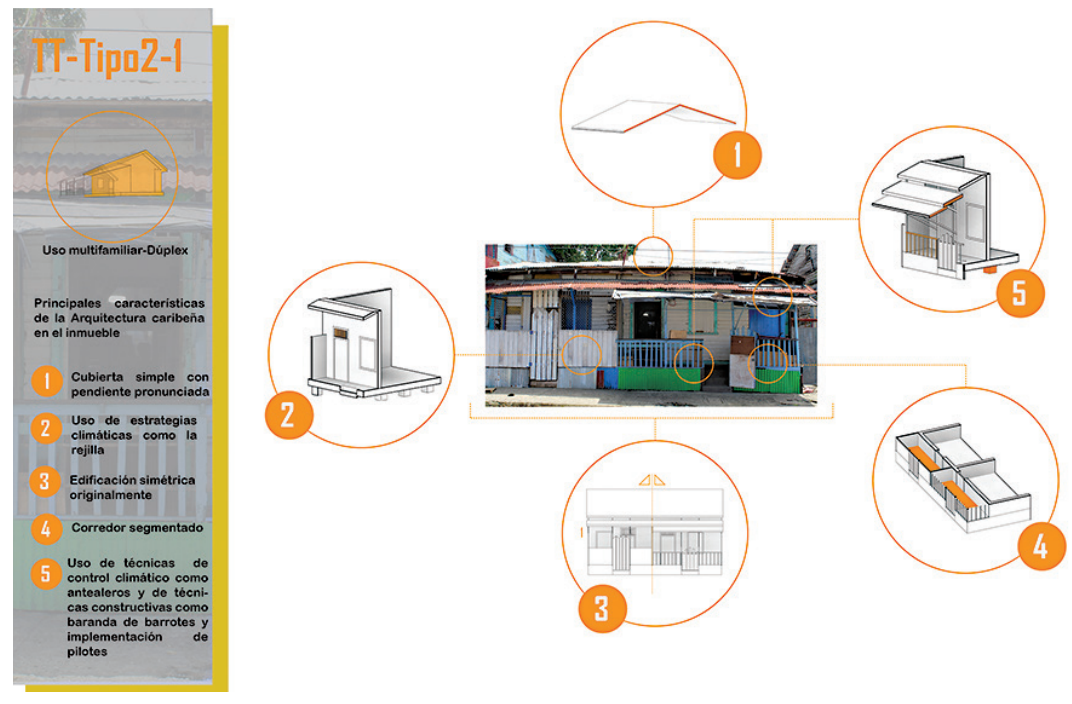

Figura 4. Ficha gráfica sobre las características caribeñas particulares, presentes en una vivienda en el Centro Histórico de Limón, producto de la PVP.

\section{Conclusiones y recomendaciones}

Las tipologías arquitectónicas propuestas en este documento, como resultado de la Práctica de Vinculación Profesional, ponen en valor la arquitectura caribeña costarricense ya que con estas 
se identifican, se registra y se delimitan los valores histórico-arquitectónicos ligados a las obras construidas en el Centro Histórico de la ciudad de Limón y su primer ensanche.

La arquitectura caribeña en madera realizada a principios del siglo XX en territorio costarricense se concretó mayoritariamente en edificaciones para fines residenciales y en menor medida en inmuebles no residenciales. Sin embargo, por la misma función utilitaria a la que responden, son las que más se han visto deterioradas y transformadas con el paso del tiempo.

Por otra parte, las seis tipologías propuestas de las obras arquitectónicas de estilo caribeño costarricense, presentes en el Centro Histórico y primer ensanche de la ciudad de Limón, sientan sus bases en la función utilitaria, la permeabilización y los niveles que presentan dichos inmuebles, al ser las características que más reflejan el modo de vida de las personas dentro de la dinámica social.

Además, el análisis de las otras expresiones formales de la arquitectura caribeña tomadas en cuenta, tales como: cubiertas, antealeros, elevación de la obra, simetría, detalles constructivos aplicados por estética de la obra y aquellas que respondían a potenciar el confort del espacio interno; permitieron distinguir todas las variantes que se presentan en los inmuebles analizados y así por diferenciarlos entre si.

Finalmente, uno de los retos que se presentaron a la hora de ejecutar la Práctica de Vinculación Profesional, fue la poca documentación escrita y publicada sobre la arquitectura caribeña costarricense; por lo tanto, este documento llega a aportar tanto al proyecto de investigación al cual está vinculado, como a la literatura científica relacionada con el tema.

\section{Referencias}

[1] I. Hernández-Salazar, D. Porras-Alfaro \& K. García-Baltodano, "La arquitectura caribeña costarricense en la trama urbana histórica de la ciudad de Limón entre el periodo 1871-1940", en III Congreso Internacional Hispanoamericano de Historia de la Construcción, Ciudad de México, MXC, 2019, pp. 473-479.

[2] L. Chaverri-Flores, "Centro histórico de puerto limón, transformaciones sociales que han contribuido a su patrimonialización”, Revista Trama, vol. 8, no. 1, pp. 107-149. en.-jun., 2019.

[3] M.C. Valverde-Solano, J.P. Bulgarelli-Bolaños \& M. Martínez Mora, "Centro Histórico de Limón y primer ensanche... explorando su potencial generador de desarrollo del patrimonio cultural", en I Simposio Internacional de Cultura: Exploración y Puesta en Valor, San José, CRC, 2019, pp. 50-57.

[4] K. García-Baltodano, D. Méndez-Álvarez \& I. Hernández-Salazar, "Arquitectura caribeña costarricense: recurso y oportunidad para el territorio", en I Simposio Internacional de Cultura: Exploración y Puesta en Valor, San José, CRC, 2019, pp. 113-123.

[5] M. Domínguez, "Nuevos rumbos de la arquitectura tropical caribeña", arq.urb, vol. 6, pp 4-29, dez. 2019.

[6] J.P. Bulgarelli-Bolaños, "Modelo de gestión de proyectos para la intervención de bienes inmuebles con declaratoria de patrimonio histórico-arquitectónico en Costa Rica", en I Simposio Internacional de Cultura: Exploración y Puesta en Valor, San José, CRC, 2019, pp. 124-137.

[7] J. Herrera. (2017). La investigación cualitativa [en línea]. Recuperado de https://juanherrera.files.wordpress. com/2008/05/investigacion-cualitativa.pdf

[8] C.A. Monje, Metodología de la investigación cuantitativa y cualitativa. Guía didáctica, Colombia: Neiva, 2011, p.9.

[9] J.A. Abela. (2002). Las técnicas de análisis de contenido: una revisión actualizada [en línea]. Recuperado de https://scholar.googleusercontent.com/scholar?q=cache:TFSf5ilGGW4J:scholar.google.com/+J.A.+Abela.+(2 002). +Las+t\%C3\%A9cnicas+de+an\%C3\%A1lisis+de+contenido:+una+revisi\%C3\%B3n+actualizada+\&hl=e s\&as_sdt=0,5

[10] M.B. Zayas-Fernández, "Evolución de la tipología arquitectónica y caracterización paisajística de los grandes equipamientos urbanos", Baetica. Estudios de Arte, Geografía e Historia, no. 34, pp. 103-125, 2012.

[11] M. Rodríguez-Viqueira \& L.F. Guerrero-Baca, Estudio de tipología arquitectónica 1996, Ciudad de México: Universidad Autónoma de México, 1996. 